Case Report

\title{
Mitochondrial Disease as a Cause of Neonatal Hemophagocytic Lymphohistiocytosis
}

\author{
Kazumasa Fuwa, ${ }^{1}$ Mitsuru Kubota, ${ }^{2}$ Masami Kanno, ${ }^{1}$ Hiroshi Miyabayashi, \\ Ken Kawabata, ${ }^{1}$ Keiichi Kanno, ${ }^{1}$ and Masaki Shimizu ${ }^{1}$ \\ ${ }^{1}$ Division of Neonatology, Saitama Children's Medical Center, 2100 Magome, Iwatsuki-ku, Saitama 339-8551, Japan \\ ${ }^{2}$ Department of General Pediatrics \& Interdisciplinary Medicine, National Center for Child Health and Development, \\ 2-10-1 Okura, Setagaya-ku, Tokyo 157-8535, Japan
}

Correspondence should be addressed to Mitsuru Kubota; kubota-mt@ncchd.go.jp

Received 22 June 2016; Accepted 22 August 2016

Academic Editor: Daniel K. L. Cheuk

Copyright (C) 2016 Kazumasa Fuwa et al. This is an open access article distributed under the Creative Commons Attribution License, which permits unrestricted use, distribution, and reproduction in any medium, provided the original work is properly cited.

\begin{abstract}
Diagnosis of mitochondrial respiratory chain disorder (MRCD) is often difficult. Its pathogenesis is still unclear. We diagnosed MRCD by measuring the activity of the mitochondrial respiratory chain enzyme, and the patient also had hemophagocytic lymphohistiocytosis (HLH). A preterm female infant was born at 34 weeks of gestation. On day 6, HLH was revealed by bone marrow aspiration. She died on day 10 due to uncontrollable HLH. An autopsy was performed, and we measured the activity of the mitochondrial respiratory chain enzyme in the liver, muscle, and heart. The activity of complex I was decreased in all tissues. As we could not prove another origin of the HLH, she was diagnosed as having HLH caused by MRCD. It is useful to measure the activity of the mitochondrial respiratory chain enzyme for diagnosing MRCD. MRCD, which has a severe clinical course, may be related to HLH.
\end{abstract}

\section{Introduction}

Mitochondrial respiratory chain disorders (MRCDs) are dysfunction of the oxidative phosphorylation. MRCD is the most frequently congenital metabolic disease. The frequency is $1 / 5000$ births. Half of MRCD cases are diagnosed in the neonatal period [1]. MRCDs in the neonatal period are fatal and show severe syndromes that are derived from multiple organs. Therefore, it is difficult to diagnose MRCD in the neonatal period. These pathogeneses are still unclear [2].

Hemophagocytic lymphohistiocytosis (HLH) is a hyperinflammatory disorder in an uncontrolled and ineffective immune response. HLH occurs either as a primary form or as a secondary form [3]. MRCDs as a cause of secondary form HLH are very rare.

We could diagnose MRCD by measuring the activity of the mitochondrial respiratory chain enzyme. We encountered a preterm infant who had MRCD that might have caused $\mathrm{HLH}$. In this paper, we discuss the way to diagnose MRCD and the correlation between MRCD and HLH.

\section{Case Report}

A 39-year-old woman with no gestation and no parturition became pregnant by intracytoplasmic sperm injection. There was no family history of sudden death or consanguineous marriage. At 34 weeks and 4 days of gestation, fetal hydrops (pleural effusion, ascites, and subcutaneous edema) was recognized. The infant was delivered by emergency caesarean section due to a nonreassuring fetal status. The infant was intubated due to grunting and transferred to our NICU. Apgar scores were $7(1 \mathrm{~min}) / 9(5 \mathrm{~min})$. Her weight was $2264 \mathrm{~g}$ (appropriate for dates). Her muscle tone was low. Mild retractions with no murmur and no rale were recognized. Abdominal finding was the distention with hepatosplenomegaly. No abnormal findings existed. We show laboratory findings in Table 1. Lactic acidosis had continued, and jaundice appeared within 24 hours of birth. Disseminated intravascular coagulation (DIC) was recognized. The ammonia, C-reactive protein, and ferritin levels increased. On day 1 , we measured cytokines. The findings were the 
TABLE 1: Laboratory findings on admission.

\begin{tabular}{|c|c|c|}
\hline \multirow{13}{*}{$\mathrm{CBC}$} & WBC & $25.3 \times 10^{3} / \mu \mathrm{L}$ \\
\hline & Band & $10 \%$ \\
\hline & Seg & $28.5 \%$ \\
\hline & Lymph & $47 \%$ \\
\hline & Mono & $11 \%$ \\
\hline & Eosino & $1.0 \%$ \\
\hline & Baso & $0 \%$ \\
\hline & Blast & $0 \%$ \\
\hline & $\mathrm{RBC}$ & $2.34 \times 10^{6} / \mu \mathrm{L}$ \\
\hline & $H b$ & $8.3 \mathrm{~g} / \mathrm{dL}$ \\
\hline & $\mathrm{Ht}$ & $25.1 \%$ \\
\hline & Plt & $1.7 \times 10^{4} / \mu L$ \\
\hline & Ret & $54.1 \%$ o \\
\hline \multirow{6}{*}{ Coagulation } & PT & $37.1 \mathrm{sec}$ \\
\hline & APTT & $110.7 \mathrm{sec}$ \\
\hline & $\mathrm{Fib}$ & $40 \mathrm{mg} / \mathrm{dL}$ \\
\hline & HPT & $22.6 \%$ \\
\hline & FDP & $25.1 \mu \mathrm{g} / \mathrm{dL}$ \\
\hline & AT3 & $8.8 \%$ \\
\hline \multirow{17}{*}{$\begin{array}{l}\text { Biochemistry } \\
\text { findings }\end{array}$} & T-Bil & $7.7 \mathrm{mg} / \mathrm{dL}$ \\
\hline & D-Bil & $0.2 \mathrm{mg} / \mathrm{dL}$ \\
\hline & AST & 47 IU/L \\
\hline & ALT & $6 \mathrm{IU} / \mathrm{L}$ \\
\hline & $\mathrm{CK}$ & $69 \mathrm{IU} / \mathrm{L}$ \\
\hline & BUN & $7 \mathrm{mg} / \mathrm{dL}$ \\
\hline & $\mathrm{Cr}$ & $0.61 \mathrm{mg} / \mathrm{dL}$ \\
\hline & $\mathrm{Na}$ & $138 \mathrm{mmol} / \mathrm{L}$ \\
\hline & $\mathrm{K}$ & $4.2 \mathrm{mmol} / \mathrm{L}$ \\
\hline & $\mathrm{Cl}$ & $109 \mathrm{mmol} / \mathrm{L}$ \\
\hline & $\mathrm{Ca}$ & $9.3 \mathrm{mg} / \mathrm{dL}$ \\
\hline & $\mathrm{P}$ & $5.7 \mathrm{mg} / \mathrm{dL}$ \\
\hline & $\mathrm{TP}$ & $3.2 \mathrm{~g} / \mathrm{dL}$ \\
\hline & $A L B$ & $2.0 \mathrm{~g} / \mathrm{dL}$ \\
\hline & $\mathrm{NH}_{3}$ & $156 \mu \mathrm{g} / \mathrm{dL}$ \\
\hline & Ferritin & $3701.9 \mathrm{ng} / \mathrm{mL}$ \\
\hline & CRP & $1.23 \mathrm{mg} / \mathrm{dL}$ \\
\hline Blood type & $\mathrm{O} \mathrm{Rh}(+)$ & \\
\hline \multirow{4}{*}{ Immunological } & $\operatorname{IgG}$ & $333 m g / d L$ \\
\hline & $\operatorname{Ig} A$ & $0 \mathrm{mg} / \mathrm{dL}$ \\
\hline & IgM & $12 \mathrm{mg} / \mathrm{dL}$ \\
\hline & Direct Coombs test & $(-)$ \\
\hline \multirow{2}{*}{$\begin{array}{l}\text { Peripheral } \\
\text { smear }\end{array}$} & Spherocytosis & $(-)$ \\
\hline & Elliptocytosis & $(-)$ \\
\hline \multirow{7}{*}{$\begin{array}{l}\text { Blood gas } \\
\text { analysis (artery } \\
\text { intubated) }\end{array}$} & $\mathrm{pH}$ & 7.340 \\
\hline & $\mathrm{O}_{2}$ & $154.3 \mathrm{mmHg}$ \\
\hline & $\mathrm{CO}_{2}$ & $24.5 \mathrm{mmHg}$ \\
\hline & $\mathrm{HCO}_{3}^{-}$ & $12.9 \mathrm{mmol} / \mathrm{L}$ \\
\hline & $B E$ & $-10.8 \mathrm{mmol} / \mathrm{L}$ \\
\hline & Lac & $70.1 \mathrm{mg} / \mathrm{dL}$ \\
\hline & Anion gap & 16.1 \\
\hline $\begin{array}{l}\text { Chromosomal } \\
\text { test ( } \mathrm{G} \text { band) } \\
\end{array}$ & $46, X X$ & \\
\hline
\end{tabular}

This table shows all laboratory findings on admission. Bold font: high; italic font: low.

following: IL-6 level $1398.3 \mathrm{pg} / \mathrm{mL}$, IL-8 $21675.0 \mathrm{pg} / \mathrm{mL}$, INF- $\gamma$ $5>\mathrm{pg} / \mathrm{mL}$, and TNF- $\alpha 8.2 \mathrm{pg} / \mathrm{mL}$. The findings showed hypercytokinemia. We performed an exchange transfusion three times (twice on day 1 and once on day 2) for the early onset jaundice. The patient had prolonged lactic acidosis, mild hyperammonemia, and liver failure that was similar to the presentation of Reye syndrome. Laboratory change, which is related to liver failure, is shown in Figure 1(a). Neonatal mass screening by tandem mass spectrometry, amino acid analysis, and urine organic acid analysis showed normal findings. From the above results, we suspected mitochondrial disease and began to administer vitamin B1, vitamin B2, vitamin C, Carnitine, and Coenzyme Q10 on day 2. On day 5 , in the blood, lactate was $39.0 \mathrm{mg} / \mathrm{dL}$, and pyruvic acid was $1.16 \mathrm{mg} / \mathrm{dL}$ (lactate/pyruvic acid ratio of $33.2>20$ ). In the cerebral spinal fluid, lactate was $43.6 \mathrm{mg} / \mathrm{dL}$, and pyruvic acid was $1.73 \mathrm{mg} / \mathrm{dL}$ (lactate/pyruvic acid ratio of $25.2>20$ ). These results were also suggesting that she was mitochondrial disease. Thrombocytopenia and anemia did not improve. Specifically, thrombocytopenia was severe, and the patient received continuous platelet transfusion (Figure 1(b)). On day 6 , we performed bone marrow aspiration, because mitochondrial disease was not enough for explaining pathogenesis of thrombocytopenia. We recognized a large amount of hemophagocytic macrophages, and we could not detect any evidence of malignancy. She was afebrile. However, the splenomegaly continued from admission. Other examination findings were as follows: WBC $11.4 \times 10^{3} / \mu \mathrm{L}, \mathrm{Hb} 7.9 \mathrm{~g} / \mathrm{dL}$, Plt $2.4 \times 10^{4} / \mu \mathrm{L}$, fibrinogen $74 \mathrm{mg} / \mathrm{dL}$, and soluble IL-2 receptor $3805 \mathrm{U} / \mathrm{mL}$. Although we could not measure fasting triglycerides and NK cell activity, our case was diagnosed as hemophagocytic lymphohistiocytosis (HLH), because she had five criteria of Revised Diagnostic Guidelines for HLH [4]. We began to administer prednisolone $(2 \mathrm{mg} / \mathrm{kg} /$ day $)$ on day 6 and cyclosporine $(1 \mathrm{mg} / \mathrm{kg} /$ day) on day 8 to treat HLH. We also administered immunoglobulin $(500 \mathrm{mg} / \mathrm{kg})$ on day 8 . On day 10, the patient died due to uncontrollable HLH, and an autopsy was performed after parental consent was given to perform the autopsy on the whole body except for her brain.

We took samples from the liver, muscle, and heart, and they were preserved at $-80^{\circ} \mathrm{C}$. Activities of the mitochondrial respiratory chain complexes I, II, III, and IV were assayed as described previously [5]. In these assays, citrate synthase (CS) was used as a housekeeping mitochondrial enzyme marker. The percent ratio of complex I activity to CS activity was decreased in all tissues (Table 2). We diagnosed MRCD (mitochondrial complex I deficiency) based on the diagnostic criteria given by Bernier et al. [6].

According to the results above, she was diagnosed as having MRCD with HLH. We could not detect an antecedent infection (Table 3). Although the mutation of PRF1 is the most common genetic mutation of primary HLH in Japan, she had no mutation of PRF1.

\section{Discussion}

We determined two important clinical issues. First, it is useful to measure the activity of the mitochondrial respiratory chain enzyme for diagnosing MRCD. Second, MRCD, which has a severe clinical course, may be related to HLH. 


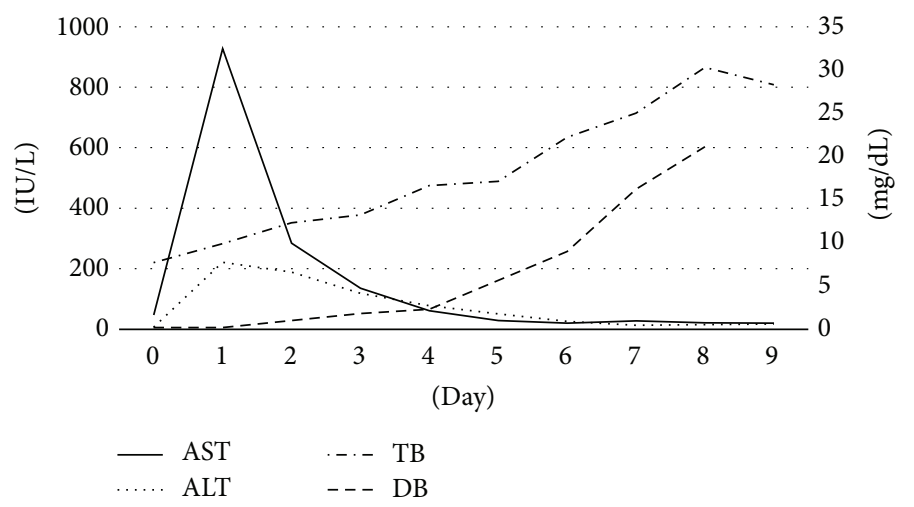

(a)

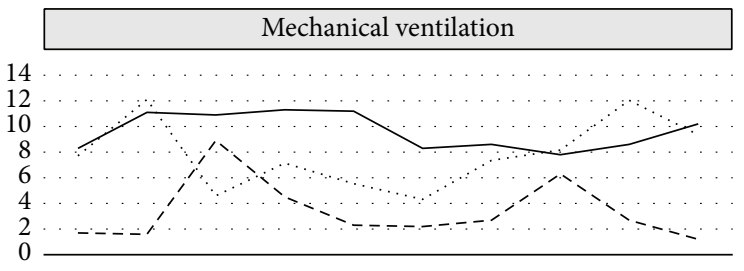

- - Plt $(\times 104 / \mu \mathrm{L})$

$-\mathrm{Hb}(\mathrm{g} / \mathrm{dL})$

..... Lactate (mmol/L)

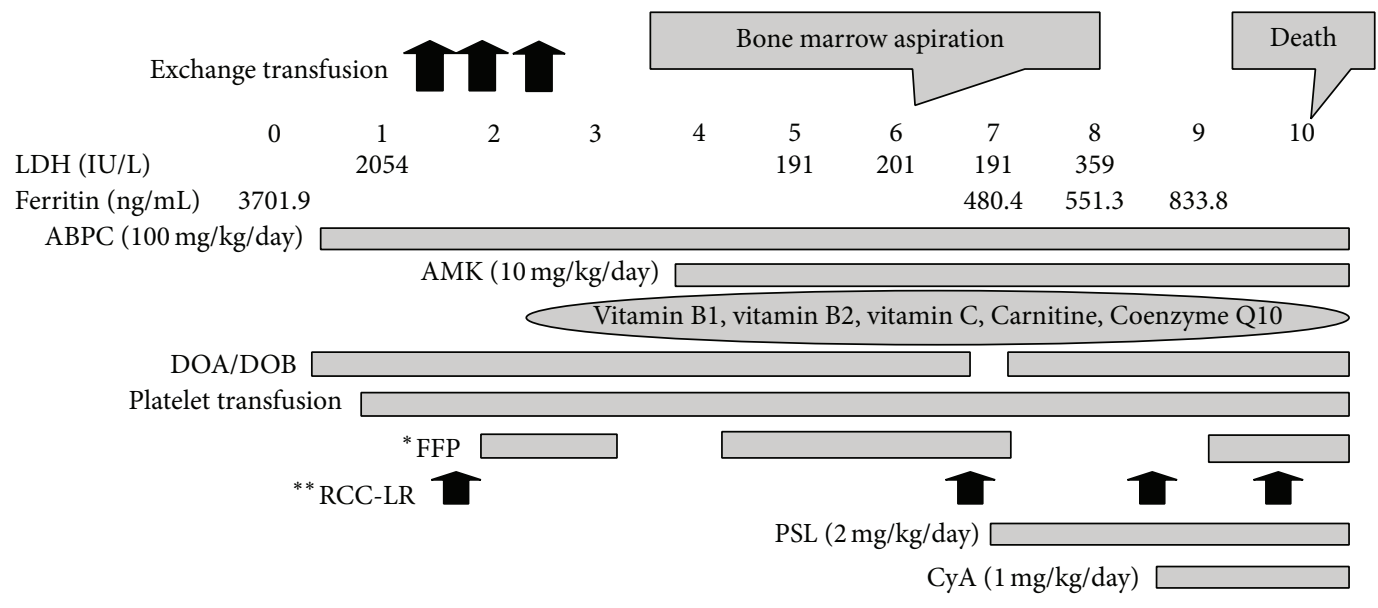

$\gamma$-glb

(b)

Figure 1: (a) Clinical course which is related to liver dysfunction. This figure shows the laboratory findings that are related to liver function. In a few days after birth, severe liver failure with a dominant increase in unconjugated bilirubin was evident. After that, aspartate aminotransferase and alanine aminotransferase levels were decreased; on the other hand, conjugated bilirubin level was increased. (b) Clinical course while she was hospitalized. This figure shows the clinical course of the patient. Thrombocytopenia did not improve after continuous platelet transfusion. Administration of vitamin B1, vitamin B2, vitamin C, Carnitine, and Coenzyme Q10 is a supporting therapy for mitochondrial disease. ${ }^{*}$ FFP: fresh frozen plasma. ${ }^{*}$ RCC-LR: red cell concentrates-leukocyte reduced.

The diagnostic criteria given by Bernier et al. is useful for diagnosing MRCD [6]. This diagnosis requires one of the following: enzymology, histology, functional assay, or molecular assay.

Enzymatic diagnosis of MRCD is achieved by the activity of the mitochondrial respiratory enzyme. We can accurately measure the activity of the mitochondrial respiratory chain enzyme, as we appropriately take a sample and immediately preserve it at $-80^{\circ} \mathrm{C}$ [7]. We can determine the biological function of the mitochondria by measuring the activity of the mitochondrial respiratory chain enzyme. In histology, the fact that there are $>2 \%$ ragged red fibers in the skeletal 
TABLE 2: Enzyme assay of the mitochondrial respiratory chain (IIV).

(a) Liver

\begin{tabular}{lccccc}
\hline$\%$ & Co I $^{*}$ & Co II $^{* *}$ & Co III $^{* * *}$ & Co IV $^{\dagger}$ & CS $^{\dagger \dagger}$ \\
\hline Patient & & & & & \\
\% of normal & 15 & 31 & 78 & 100 & 108 \\
CS ratio (\%) & 13 & 28 & 68 & 88 & \\
Co II ratio (\%) & 46 & & 242 & 252 & \\
\hline
\end{tabular}

(b) Muscle

\begin{tabular}{lcccccc}
\hline$\%$ & Co I & Co II & Co II + III & Co III & Co IV & CS \\
\hline Patient & & & & & & \\
\% of normal & 17 & 54 & 57 & 51 & 35 & 63 \\
CS ratio (\%) & 26 & 86 & 89 & 83 & 52 & \\
Co II ratio (\%) & 30 & & 100 & 94 & 57 & \\
\hline
\end{tabular}

(c) Heart

\begin{tabular}{lcccccc}
\hline$\%$ & Co I & Co II & Co II + III & Co III & Co IV & CS \\
\hline Patient & & & & & & \\
\% of normal & 15 & 89 & 53 & 159 & 63 & 112 \\
CS ratio (\%) & 14 & 79 & 46 & 142 & 57 & \\
Co II ratio (\%) & 26 & & 76 & 220 & 46 & \\
\hline
\end{tabular}

This table shows the activity of the mitochondrial respiratory chain enzyme (I-IV) in the liver, muscle, and heart.

${ }^{*}$ Co I: complex. ${ }^{* *}$ Co II: complex II. ${ }^{* * *}$ Co III: complex III. ${ }^{\dagger}$ Co IV: complex IV. ${ }^{\dagger \dagger} \mathrm{CS}$ : citrate synthase.

muscle is necessary for diagnosis; however, ragged red fibers are not common in children. Functional assays require the culture of fibroblasts, which takes a few months. Molecular assays are sometimes difficult. Calvo et al. reported exome sequencing of $42 \mathrm{MRCD}$ patients, and only $24 \%$ of these patients had mutations in genes that have previously been linked to disease. $31 \%$ of them had mutations in nuclear genes that had never been linked to disease. $45 \%$ of them did not have any mutations [8]. Kohda et al. reported a comprehensive genetic analysis about 142 childhood-onset MRCDs. It revealed that 40 patients $(28.2 \%)$ did not have any mutation in nuclear gene, mitochondrial DNA, and chromosome [9].

HLH might be secondary to MRCD. However, it is possible that HLH causes MRCD. It is well known that tumor necrosis factor (TNF) injures mitochondria and induces reactive oxygen species (ROS) production [10]. In our case, TNF- $\alpha$ was not so high. Therefore, it is difficult to interpret our case as secondary mitochondrial dysfunction due to hyperexcretion of TNF- $\alpha$. In animal models, when the mitochondrial complex I is inhibited, the mitochondrial ROS production increases $[11,12]$. Weinberg et al. reported that inflammatory cytokines are activated by mitochondrial generated ROS [13]. Therefore, in our case, we hypothesize that mitochondrial complex I deficiency causes ROS production, and HLH is induced by hypercytokinemia following the ROS.

Half of MRCD cases are diagnosed in the neonatal period, and $35 \%$ of the patients were diagnosed as having
TABLE 3: Laboratory findings about antecedent infection.

\begin{tabular}{|c|c|c|}
\hline & Blood & \\
\hline & Toxoplasma & $\operatorname{Ig} M(-)$ \\
\hline & Parvovirus B19 & $\operatorname{IgM}(\mathrm{EIA})(-), \operatorname{PCR}(-)$ \\
\hline & Rubella & $\operatorname{IgM}(\operatorname{EIA})(-), \operatorname{PCR}(-)$ \\
\hline & Herpes simplex virus & $\operatorname{IgM}(\operatorname{EIA})(-), \operatorname{PCR}(-)$ \\
\hline & Cytomegalovirus & $\operatorname{IgM}(\mathrm{EIA})(-), \operatorname{PCR}(-)$ \\
\hline Infection & Epstein-Barr virus & $\operatorname{PCR}(-)$ \\
\hline & Urine & \\
\hline & Cytomegalovirus & $\operatorname{PCR}(-)$ \\
\hline & $\begin{array}{l}\text { Primary isolation of } \\
\text { virus (day } 7 \text { ) }\end{array}$ & $(-)$ \\
\hline & Feces $\cdot$ throat & \\
\hline & $\begin{array}{l}\text { Primary isolation of } \\
\text { virus (day } 7 \text { ) }\end{array}$ & $(-)$ \\
\hline
\end{tabular}

This table shows the laboratory findings regarding antecedent infection. We took samples for primary isolation of virus on day 7. The other samples were taken on admission. All findings were negative.

lethal infantile mitochondrial disorders [1]. As the symptoms of MRCD are nonspecific, the diagnosis is sometimes difficult. Therefore, MRCD may be the cause of the cryptogenic neonatal deaths that have severe clinical courses. HLH may be related to MRCD, which has a severe clinical course.

Cases involving both MRCD and HLH are rare, and we have experienced only one case. We must inform neonatologists about MRCD, because onset of MRCD is during the neonatal period. Then a further study of MRCD should be conducted.

\section{Conclusion}

We recommend that an assay of the mitochondrial respiratory chain enzyme should be performed if mitochondrial disease is suspected. MRCD may be related to the pathogenesis of secondary HLH.

\section{Consent}

The parents have consented to the submission of this case report to the journal.

\section{Disclosure}

Present address of Kazumasa Fuwa is Department of Pediatrics and Child Health, Nihon University School of Medicine, Oyaguchi 30-1, Itabashi, Tokyo 173-8610, Japan.

\section{Competing Interests}

The authors declare that there is no conflict of interests regarding the publication of this paper. 


\section{Acknowledgments}

The authors thanks Dr. Kei Murayama (Department of Metabolism, Chiba Children's Hospital) for measuring the activity of the mitochondrial respiratory chain enzyme, Associate Professor Hirokazu Kanegane (Department of Pediatrics, Tokyo Medical and Dental University Hospital) for detecting genetic mutations of primary HLH, Dr. Hiroshi Kishimoto (Division of Pathology, Saitama Children's Medical Center) for performing the autopsy, and Dr. Yuki Arakawa (Division of Hematology \& Oncology, Saitama Children's Medical Center) for diagnosing HLH.

\section{References}

[1] T. Yamazaki, K. Murayama, A. G. Compton et al., "Molecular diagnosis of mitochondrial respiratory chain disorders in Japan: focusing on mitochondrial DNA depletion syndrome," Pediatrics International, vol. 56, no. 2, pp. 180-187, 2014.

[2] S. DiMauro and E. A. Schon, "Mitochondrial respiratory-chain diseases," The New England Journal of Medicine, vol. 348, no. 26, pp. 2656-2668, 2003.

[3] H. R. Freeman and A. V. Ramanan, "Review of haemophagocytic lymphohistiocytosis," Archives of Disease in Childhood, vol. 96, no. 7, pp. 688-693, 2011.

[4] J.-I. Henter, A. Horne, M. Aricó et al., "HLH-2004: diagnostic and therapeutic guidelines for hemophagocytic lymphohistiocytosis," Pediatric Blood \& Cancer, vol. 48, no. 2, pp. 124-131, 2007.

[5] K. Murayama, H. Nagasaka, T. Tsuruoka et al., "Intractable secretory diarrhea in a Japanese boy with mitochondrial respiratory chain complex I deficiency," European Journal of Pediatrics, vol. 168, no. 3, pp. 297-302, 2009.

[6] F. P. Bernier, A. Boneh, X. Dennett, C. W. Chow, M. A. Cleary, and D. R. Thorburn, "Diagnostic criteria for respiratory chain disorders in adults and children," Neurology, vol. 59, no. 9, pp. 1406-1411, 2002.

[7] M. J. Menezes, L. G. Riley, and J. Christodoulou, "Mitochondrial respiratory chain disorders in childhood: insights into diagnosis and management in the new era of genomic medicine," Biochimica et Biophysica Acta (BBA)_General Subjects, vol. 1840, no. 4, pp. 1368-1379, 2014.

[8] S. E. Calvo, A. G. Compton, S. G. Hershman et al., "Molecular diagnosis of infantile mitochondrial disease with targeted nextgeneration sequencing," Science Translational Medicine, vol. 4, no. 118, Article ID 118ra10, 2012.

[9] M. Kohda, Y. Tokuzawa, Y. Kishita et al., "A comprehensive genomic analysis reveals the genetic landscape of mitochondrial respiratory chain complex deficiencies," PLoS Genetics, vol. 12, no. 1, Article ID e1005679, 2016.

[10] K. Schulze-Osthoff, A. C. Bakker, B. Vanhaesebroeck, R. Beyaert, W. A. Jacob, and W. Fiers, "Cytotoxic activity of tumor necrosis factor is mediated by early damage of mitochondrial functions: evidence for the involvement of mitochondrial radical generation," The Journal of Biological Chemistry, vol. 267, no. 8, pp. 5317-5323, 1992.

[11] S. DiMauro and C. Garone, "Metabolic disorders of fetal life: glycogenoses and mitochondrial defects of the mitochondrial respiratory chain," Seminars in Fetal \&Neonatal Medicine, vol. 16, no. 4, pp. 181-189, 2011.
[12] N. Li, K. Ragheb, G. Lawler et al., "Mitochondrial complex I inhibitor rotenone induces apoptosis through enhancing mitochondrial reactive oxygen species production," The Journal of Biological Chemistry, vol. 278, no. 10, pp. 8516-8525, 2003.

[13] S. E. Weinberg, L. A. Sena, and N. S. Chandel, "Mitochondria in the regulation of innate and adaptive immunity," Immunity, vol. 42, no. 3, pp. 406-417, 2015. 


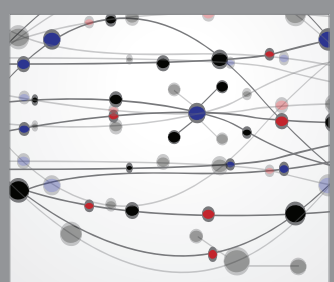

The Scientific World Journal
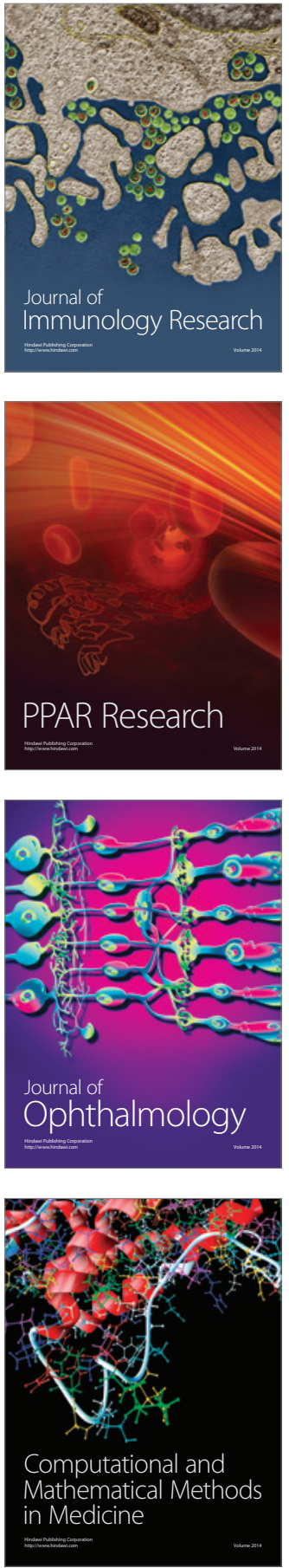

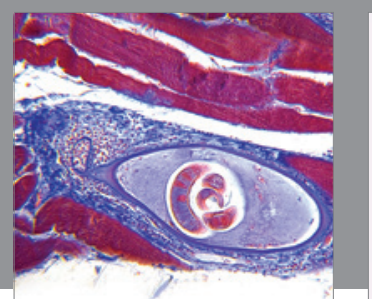

Gastroenterology Research and Practice

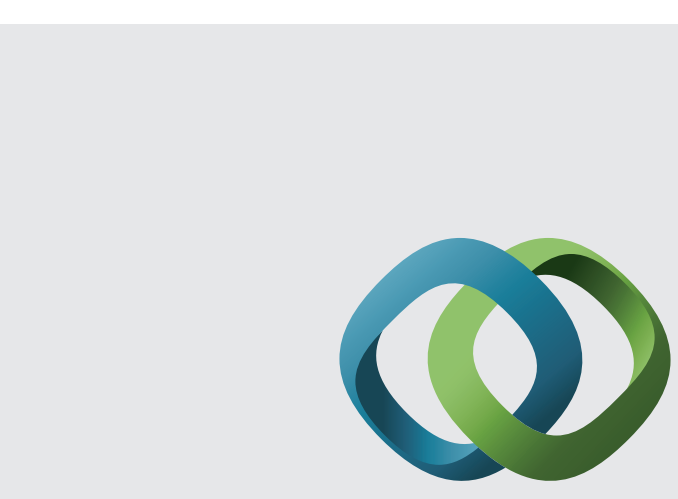

\section{Hindawi}

Submit your manuscripts at

http://www.hindawi.com
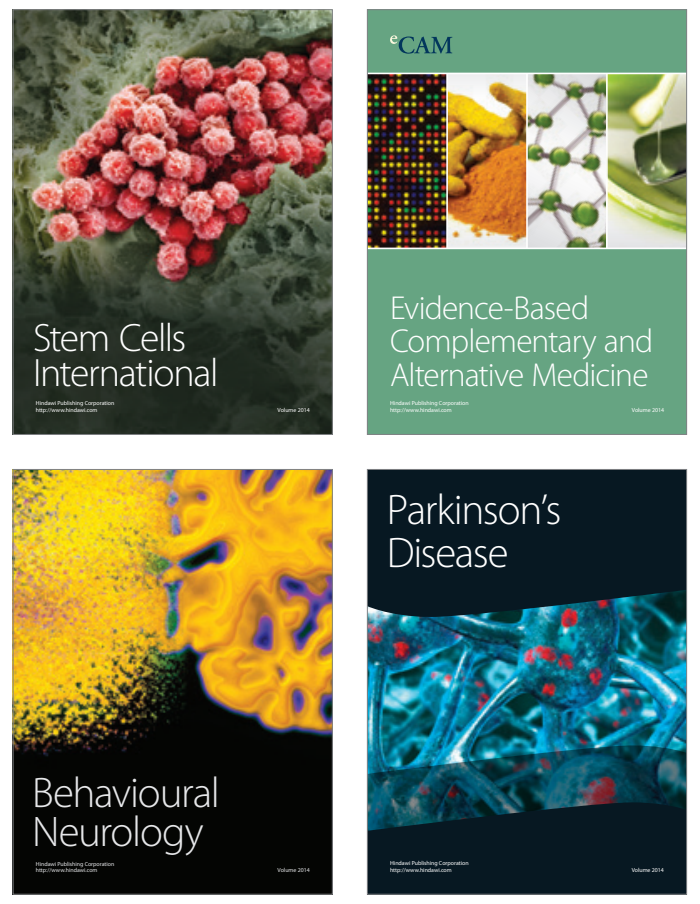
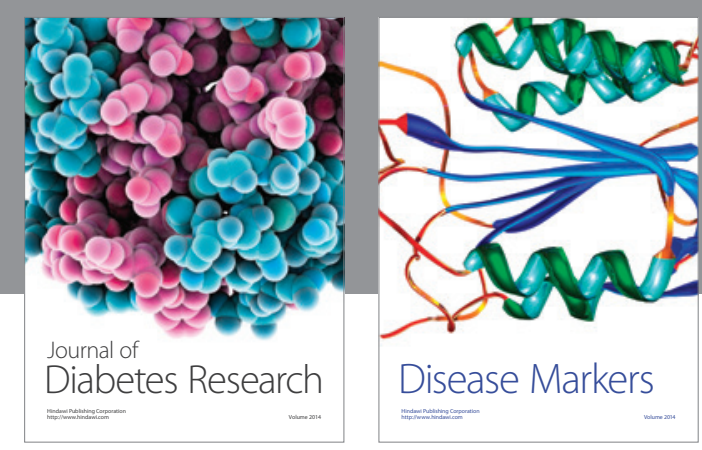

Disease Markers
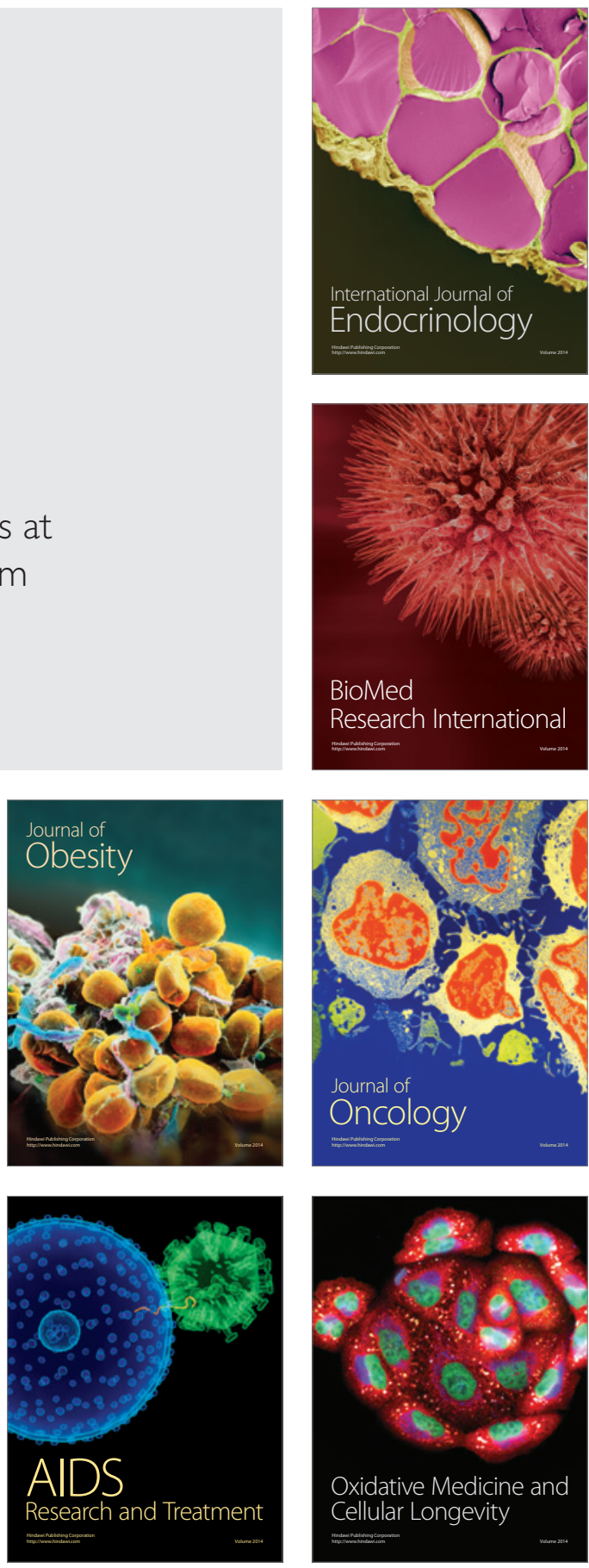